\title{
On the way towards zero discrimination; What do people living with HIV think?
}

\section{Gunathilake M P W' ${ }^{1}$, Samarakoon $S^{1}$}

Background: Sri Lanka is a country with a low prevalence of HIV infection. Nevertheless, number of people infected with HIV continues to rise with a considerable gap between the number identified and estimated. It is well known that stigma and discrimination to people living with HIV play a major role preventing people accessing services for HIV testing, care and support, worldwide.Sri Lanka is no exception.

Methods: We interviewed $102 \mathrm{HIV}$ patients using an interviewer administered questionnaire. In depth interviews were conducted with some of them.

Results: Major discrimination was within the health sector with $43 \%$ being discriminated at health care settings. $28.4 \%$ of them had to undergo testing for HIV, before foreign employment. The rates of voluntary testing were very low. $80 \%$ of people living with HIV (PLHIV) have disclosed the positive status, someone else.

Conclusions: A multi sectoral approach is necessary to provide care, support and treatment without stigma and discrimination. There should be self help groups of PLHIV to help each other and to liaise with healthcare personnel when required.

Key words: HIV, AIDS, Stigma, Discrimination, Human rights

\section{Introduction}

HIV/AIDS is the most devastating catastrophe mankind has ever faced ( delete). Many millions of people have been affected by HIV/AIDS and many have died during these four decades of the pandemic. In spite of many efforts, the disease continues to spread. No country or race has been unaffected.
Interventions to get ahead of the HIV epidemic, are hampered by stigma and discrimination to people living with HIV(PLHIV), which continue to exist and slowdowns both preventive and treatment programmes. The goal of universal access will not be achieved unless activities to reduce or eliminate stigma and discrimination of HIV infected people are prioritized in national prevention programmes (1).

Stigma is defined as any attribute that has a discrediting effect on an individual's character (2). When stigma is acted upon, the result is discrimination. The HIV/AIDS epidemic has created opportunities for the manifestation of stigma due to its connection with homosexuality, prostitution, drug use, as well as the powerful images associating HIV with death, guilt, punishment and its incurable nature (3).It plays into and reinforces social inequalities linked to gender, race, and ethnicity and sexuality (4).

This report includes some components of the study which we thought as directly related to provision of health care to PLHIV.

\section{Methods}

The study was carried out at the Central STD Clinic of the National STD/AIDS Control Programme (NSACP) in Colombo, which is the institution with the biggest number of HIV positive patients. Ethical approval was given by the Ethical Review Committee of the Faculty of Medicine, University of Kelaniya.

A descriptive cross sectional study consisting of both qualitative and quantitative components was carried out for three months. All eligible patients, who gave informed consent, were enrolled consecutively. Patients who were less than eighteen years, mentally handicapped, or with psychiatric disorders and patients diagnosed one month prior from the day of recruitment to the study were excluded. 
Quantitative data was analyzed using SPSS version 16. Consolidated narratives were prepared using qualitative data

\section{Results}

102 participated out of 108 eligible patients in the quantitative component of the study. Non response rate was $7.4 \%$.

\section{Demographic characteristics}

Ninety percent of the study sample was below 49 years of age. Highest proportion $(29.4 \%)$ was observed in 40- 44 age group followed by 45-49 age group $(20.6 \%)$. Mean age of the participants was 40.2 years with an age range of 22-57 years.

There were 55 males (54\%) and 47 females (46\%). Male to female ratio was 1.17: 1. Fifty five percent $(\mathrm{n}=56)$ of the study population was married. There were $17.6 \%$ widows $(n=18), 15.7 \%$ were separated or divorced $(\mathrm{n}=16)$ from their partners and $11.8 \%$ were single $(n=12)$.

\section{Discrimination and healthcare}

As shown in table 1, most PLHIV ( $\mathrm{n}=63$ ) perceived their health status as good or moderately good. Twenty five (53\%) females and 27 (49\%) males in the study reported taking antiretroviral therapy. Overall $43 \% \quad(n=44)$ of them reported being discriminated in health care settings. More females were subjected to discrimination than males $(\mathrm{p}=0.55)$. Nearly one fifth (18.6\%) of the study population have experienced discrimination only once in life, nearly four percent $(3.9 \%)$ of the population thought they are being constantly discriminated. Healthcare workers have refused treatment to $14 \%$ of patients because of HIV infection. In the study group, 16 (15.7 $\%)$ have experienced delays in treatment at health institutions because of their positive HIV status. The majority $(84.3 \%)$ of the study population have not experienced such delays.

Table 1: Healthcare and discrimination

\begin{tabular}{|l|l|l|l|}
\hline & Female & Male & Total \\
\hline Perceived health status & & \\
\hline Vcry good & $13(27.7 \%)$ & $17(30.9 \%)$ & $30(29.4 \%)$ \\
\hline Moderately good & $30(63.8 \%)$ & $33(60.0 \%)$ & $63(61.8 \%)$ \\
\hline Unwcll & $04(8.5 \%)$ & $05(9.1 \%)$ & $09(8.8 \%)$ \\
\hline Currently on anti retroviral therapy (ART) & $25(53.2 \%)$ & $27(49.1 \%)$ & $52(51 \%)$ \\
\hline Experienced discrimination by health care workers \\
\hline Yes & $22(46.8 \%)$ & $22(40.0 \%)$ & $44(43.1 \%)$ \\
\hline No & $24(51.1 \%)$ & $33(60 \%)$ & $57(55.9 \%)$ \\
\hline Do not know $01(2.1 \%)$ & 00 & $01(1.0 \%)$ \\
\hline Refusal of treatment by healthcare workers due to HIV \\
\hline Yes & $10(21.3 \%)$ & $05(9.1 \%)$ & $15(14.7 \%)$ \\
\hline No & $37(78.7 \%)$ & $50(90.9 \%)$ & $87(85.3 \%)$ \\
\hline Delays of treatment at healthcare settings due to HIV & \\
\hline Yes & $09(19.1 \%)$ & $07(12.7 \%)$ & $16(15.7 \%)$ \\
\hline No & $38(80.9 \%)$ & $48(87.3 \%)$ & $86(84.3 \%)$ \\
\hline
\end{tabular}

\section{Testing for HIV}

According to table 2, major reason for testing was prior to foreign employment (28.4\%). About one fifth (21.6\%) of PLHIV were tested due to HIV associated symptoms with $19.1 \%$ of females and $23.6 \%$ being tested and detected due to such symptoms. Partner's HIV infection was the reason for testing in $16.7 \%$ of study population. Eight patients $(6.9 \%)$ have been diagnosed after blood donation. 
Majority (72.5\%) of them were informed about their test before undergoing the testing for HIV. About a quarter have not received the positive results confidentially. Health care workers have disclosed
HIV status in $33 \%$ ( $\mathrm{n}=34$ ) of PLHIV, to others, without seeking consent from the PLHIV. Majority (79.4\%) of PLHIV have disclosed their HIV positive status to someone else.

\section{Table 2: Issues related to testing for HIV}

\begin{tabular}{|l|l|l|l|}
\hline Reason for testing & \multicolumn{1}{c}{ Temale } & \multicolumn{1}{c|}{ Total } \\
\hline Foreign employment & $16(34 \%)$ & $13(23.6 \%)$ & $29(28.4 \%)$ \\
\hline Pregnancy & $01(2.1 \%)$ & 00 & $01(1.0 \%)$ \\
\hline Due to symptoms & $09(19.2 \%)$ & $13(23.6 \%)$ & $22(21.6 \%)$ \\
\hline Partner's HIV status & $11(23.4 \%)$ & $06(10.9 \%)$ & $17(16.7 \%)$ \\
\hline Voluntary & 00 & $09(16.4 \%)$ & $09(8.8 \%)$ \\
\hline Blood donation & $01(2.1 \%)$ & $06(10.9 \%)$ & $07(6.9 \%)$ \\
\hline Context of HIV testing & $37(78.7 \%)$ & $37(67.3 \%)$ & $74(72.5 \%)$ \\
\hline Informed to undergo HIV test & $03(6.4 \%)$ & $01(1.8 \%)$ & $04(3.9 \%)$ \\
\hline Coerced to take HIV test & $11(23.4 \%)$ & $14(25.5 \%)$ & $25(24.5 \%)$ \\
\hline Results not given confidentially & \multicolumn{3}{|c|}{} \\
\hline HIV status divulged to other without consent by HCWs & $21(38.2 \%)$ & $34(33.3 \%)$ \\
\hline Yes & $13(27.7 \%)$ & $33(60.0 \%)$ & $65(63.7 \%)$ \\
\hline No & $32(68.1 \%)$ & $81(79.4 \%)$ \\
\hline HIV status disclosed to others by themselves & $31(20.6 \%)$ \\
\hline Yes & $36(76.6 \%)$ & $45(81.8 \%)$ \\
\hline No & $11(23.4 \%)$ & $10(18.2 \%)$ & $2 \%$ \\
\hline
\end{tabular}

\section{Why and how they were tested for HIV $-90 \%$ of participants were not happy about the way, HIV test was performed in them.}

'I was admitted to the hospital many times with fever and cough and once doctors wanted to investigate for TB. They took blood and sputum and sent me home. Then I received a telegram from the hospital asking me to come back. When I went there, they sent me to another clinic with an attendant from the hospital, without telling me the reason. There I was told about the positive test. I was shocked! Why did they do the HIV test without telling me?'

'I was a regular blood donor. Few days after donating blood I received a letter from blood bank requesting me to come back. When I went there, they asked me to get in to an ambulance quickly and sent me to Colombo, which was more than 100 kilometers away from my home, where I was told about the HIV results. I don't know why they sent me to Colombo without telling me the reason. I didn't have money even to buy food and was not prepared to travel that long.'

'I was admitted to a private hospital for treatment of frequent episodes of fever and a doctor said he was going to check me for three diseases and blood samples were sent to a lab (through my wife).When my wife went to the lab to collect the reports they refused to give reports to my wife and told her to send me there. But when my wife came back to the hospital, nurses told her that I was suffering from HIV. The lab has informed the results to the hospital staff, and confidentiality was not maintained.'

'I was suffering from many illnesses and admitted to many hospitals time to time. But they didn't consider testing for HIV. Many months later one doctor referred me to STD clinic for HIV test, and I was positive.' 


\section{Discrimination experienced at the health care settings.}

'When I was referred from the HIV clinic to another special clinic, a nurse wanted to know how I acquired, HIV and I refused answering. She became very angry and insulted me for acquiring a dirty disease'.

'When I was admitted to a hospital with HIV, one attendant spread the news to my village. As soon as I arrived my home, "a special officer" in my village came to inquire about it. Luckily the hospital hasn't mentioned my HIV results in the medical certificate and I could show it to satisfy him.'

'When I was admitted to the hospital with HIV, the nurses told my wife to earn more money and prepare for my death and she was devastated.

'When I went to get my CD4 test, there were many student nurses in that room. The nurse who did the test warned the students - to be careful when there are patients like me.'

'One doctor insulted me saying I got HIV due to bad behavior'.

'The nurse in the ante natal ward told me not to sit on the chairs of that clinic. So I had to stand for a long time, until a doctor allowed me to sit'

'When my baby was admitted to the hospital, nurses didn't sterilize her feeding bottles even though they did it for other children, My baby developed loose motions and passed away few days after'

'I feel discriminated at my regular clinic as well. Whenever there is a new doctor they want to know how I acquired the disease. Why don't they go through my clinic notes to find it out, if they want to know? I want to forget that bitter past'

\section{Discussion}

There were no patients who were eligible and not commenced on antiretroviral therapy (ART), indicating that there is no discrimination on the part of health care providers in providing ART. Among those who were on ART there was no significant gender difference observed. This confirms that there is no gender discrimination in the health service of Sri Lanka, when compared to some other countries (5). But considerable discrimination to PLHIV seems to take place at healthcare institutions. Most PLHIV tend to disclose their HIV status within health care settings and they should be encouraged to disclose their status to health care workers, for proper management of patients. It is necessary to educate health care workers in government and private institutions about the modes of transmission and non transmission and the fact that PLHIV also have a right to health care as other people in the country.

Many patients have been tested prior to foreign employment and the rates of voluntary testing have been very low. Voluntary counseling and testing should be promoted all over the country, including places like foreign travel agencies. Mandatory testing by destination or host countries should be discouraged by implementing policies for testing.

Breeches of confidentiality have been reported most of the time by health care workers. Steps should be taken to study the reasons for not respecting ethical issues and to introduce interventions to minimize them. People living with HIV should also be educated about the importance of shared confidentiality. 


\section{Limitations}

There were several limitations to this study. It was limited to patients attending the central STD clinic, Colombo; hence the findings of the study cannot be generalized. Ideally this should have been conducted in a randomly selected sample of patients with HIV. However it was difficult due to issues of confidentiality, time and financial constraints.

Interviewers had to be selected from the same institution due to confidentiality issues. When the care givers are involved in this type of study, respondents tend to hide their real experience and information bias can occur, to a certain extent.

\section{References}

1. Reducing stigma and discrimination: A critical part of national AIDS programmes. A resource for national stake holders in the HIV response. UNAIDS. 2007; 4 - 40.

2. Goffman E. Stigma: Notes on the management of spoiled identity. New York: Simon and Shuster: 1963

3. Herek G. AIDS and Stigma. American Behavioral Scientist. 1999; 42(7):1102 - 1112

4. Parker R. Aggleton P. HIV and AIDS related stigma and discrimination: a conceptual framework and implications for action. Social Science \& Medicine.2003; 57(1):13-24.

5. Paxton S; AIDS discrimination in Asia, 2004; $1-49$ 